\title{
Short and sporadic bouts in the 2018 US physical activity guidelines: is high- intensity incidental physical activity the new HIIT?
}

\author{
Emmanuel Stamatakis, ${ }^{1}$ Nathan A Johnson, ${ }^{2}$ Lauren Powell, ${ }^{1}$ \\ Mark Hamer, ${ }^{3,4}$ Vegar Rangul, ${ }_{1}^{5}$ Andreas Holtermann ${ }^{6}$
}

Starting and sticking to an exercise programme is challenging for most who are at risk of developing lifestyle-related chronic disease: the most physically inactive, unfit, and overweight or obese middle-aged individuals, that is, the majority of the adult population. The 2018 US Physical Activity Guidelines for Americans ${ }^{1}$ introduced a number of new elements that will undoubtedly change how we think about and promote physical activity (PA). Not to anyone's surprise, the new guidelines abandoned the unsupported by empirical evidence idea that PA needs to be accumulated in at least $10 \mathrm{~min}$ continuous bouts to be health enhancing. ${ }^{1}$ This opens new exciting opportunities to capitalise on sporadic, incidental in nature, PA to improve the population's health.

\section{INCIDENTAL PA: WHAT IS IT AND WHY IS IT APPEALING?}

Incidental PA is any activity that is part of one's daily living that is not done with the purpose of recreation or health and requires no sacrifice of discretionary time. For example, walking or cycling to move from place to place, stair climbing and active daily chores, such as carrying heavy shopping ${ }^{1}$ and house cleaning. Inherently, incidental PA does not encounter the myriad of barriers to

${ }^{1}$ Charles Perkins Centre, Prevention Research Collaboration, School of Public Health, University of Sydney, Camperdown, New South Wales, Australia ${ }^{2}$ Department of Exercise and Sports Science, University of Sydney, Sydney, New South Wales, Australia ${ }^{3}$ School of Sport Exercise and Health Sciences, Loughborough University, Loughborough, UK ${ }^{4}$ Department of Epidemiology and Public Health, University College London, London, UK

${ }^{5}$ Department of Public Health and Nursing, Norwegian University of Science and Technology, Trondheim, Norway

${ }^{6}$ Nationale Forskningscenter for Arbejdsmiljo, Copenhagen, Denmark

Correspondence to Professor Emmanuel Stamatakis, School of Public Health, University of Sydney, Sydney NSW 2006, Australia;

emmanuel.stamatakis@sydney.edu.au structured exercises, such as lack of time, costs, equipment, lack of skills or poor fitness. In itself, such a feasibility advantage may signal a turning point as fewer barriers mean that many more people can be incidentally active than recreationally active. What is far less clear is how to maximise the health impact of incidental PA and how to convince and empower people to be physically active in their daily lives. In this editorial, we address the first of these questions.

The length of each incidental PA bout can vary from a 'short and sweet' few seconds, such as climbing a few flights of stairs 3-4 times a day, ${ }^{2}$ to several minutes or even hours of active commuting, housework or shopping. Besides meeting recommended targets, incidental PA offers opportunities for brief episodes of vigorous intensity PA (VPA) which, compared with moderate intensity, provides superior 'per time unit' health benefits. ${ }^{13}$ For most practitioners, researchers and the public, VPA is synonymous with participation in continuous exercise lasting at least $20-30 \mathrm{mins}^{3}$, such as running or playing racquet sports. Conversely, few would associate incidental PA with vigorous intensity. ${ }^{4}$ Both of these misconceptions have flourished for two key reasons: (a) the inability of questionnaire-based studies to capture most sporadic and incidental PA; and (b) the overemphasis on absolute MET intensity, that is, multiples of resting metabolic rate expended during activity. Absolute intensity ignores the large variations between individuals in cardiorespiratory fitness (CRF) and RMR. For example, RMR decreases considerably with age, higher adiposity and female gender ${ }^{5}$; and correspondingly, the MET intensity of any given activity is higher in older and overweight/obese individuals and women. The online supplementary table 1 lists the absolute and corrected (for age, sex and height/weight ${ }^{6}$ ) MET values for common forms of incidental PA. Over $30 \%$ of walking scenarios cross the VPA threshold of 6 absolute METs ${ }^{7}$ and an additional $10 \%$ of all activities listed cross the 6 MET threshold after resting metabolic rate corrections. Although crude, such examples illustrate that once variations in resting metabolic rate are taken into account, a broad array of daily tasks will be classified as VPA for many adults. It is thus encouraging that the 2018 US guidelines emphasise the importance of relative intensity and acknowledge that incidental PA can be of vigorous intensity. ${ }^{1}$

\section{THE 'BEST BANG FOR BUCK FOR TIME UNIT' EXERCISE}

The time-economy advantage of $\mathrm{VPA}^{1}$ further strengthens the case for making the most of the 'best bang for the buck for time unit' incidental PA. High-intensity interval training (HIIT) is a time-efficient approach to exercise characterised by brief bursts of VPA near (typically $>80 \%$ ) or above $\mathrm{VO}_{2} \max$, interspersed with periods of low activity or rest. ${ }^{8}$ HIIT has the capacity to induce rapid peripheral adaptations (eg, activation of peroxisome-proliferator-activated receptor $\gamma$ coactivator- $1 \alpha$ and muscle mitochondrial biogenesis), as well as improve the structure and function of the cardiovascular system. These effects are linked with improvements in glycaemic control and other metabolic syndrome components and, most notably, CRF. ${ }^{8}$ High PA intensity is undoubtedly a key to these beneficial physiological changes, as the effects of very low-volume HIIT appear similar to those achieved with traditional continuous exercise.

Large population cohort studies 9 are also in agreement that any amount of VPA confers mortality gains with little or no volume dose-response. Studies that compared the volume and intensity of incidental PA are also consistent. For example, data from Copenhagen, a city where $>50 \%$ of all trips involve walking or cycling, showed that higher relative intensity of cycling, but not higher daily cycling volumes, was associated with substantial life expectancy gains and lower cardiovascular disease mortality risk. ${ }^{10}$

In other words, both experimental and epidemiological evidence point towards the superiority of occasionally reaching vigorous exertion over total exercise volume. 
TRANSLATING 'BEST BANG FOR BUCK FOR TIME UNIT' EXERCISE EVIDENCE INTO A SIMPLE MESSAGE

Despite the potential of HIIT, translation from short-term supervised interventions into population-level PA promotion is challenging, as both starting and sticking to HIIT programmes are difficult or even unattainable for the most physically inactive and least fit individuals. With time economy as the primary concern, potent solutions to physical inactivity will be realised by interpreting key HIIT principles into incidental PA patterns. For example, consider a pattern of 3-5 short (0.5-2 min) sporadic bouts of high relative intensity PA spread across a whole day. Such a sporadic incidental PA pattern scores high on the biological plausibility scale as the totality of the HIIT literature manifests remarkably consistent health and fitness benefits irrespective of the number of repetitions, duration (eg, from $6 \mathrm{~s}$ to $4 \mathrm{~min}$ ) and intensity of the various protocols. ${ }^{8}$ The regularity of the high-intensity PA stimulus that underpins the health potency of HIIT may be driving the improvements in fitness that occur through regular but short $(\approx 20 \mathrm{~s})$ stair climbing sessions among young adults. ${ }^{2}$

Such sporadic incidental PA patterns are achievable for most adults. Drawing data from the corrected MET values of the online supplementary table 1 , figure 1 illustrates two hypothetical examples of high relative intensity incidental PA patterns totalling $10 \mathrm{~min}$ per day for two physically inactive middle-aged individuals. Assuming that this virtually zero time commitment PA pattern is relatively consistent (eg, 5-6 days per week), the contribution of such sporadic HII PA towards meeting the PA guidelines ${ }^{1}$ would be significant $(\geq 2 / 3$ of the total requirement), making it a particularly attractive option for inactive, obese and other individuals in greatest need of lifestyle intervention.

\section{CONCLUSION}

The 2018 US PA guidelines opened new horizons for PA and exercise medicine practice by recognising that any bouts of PA count for health. ${ }^{1}$ Building a daily routine that incorporates brief sporadic bouts of high relative intensity incidental PA has numerous practical and health advantages. The next step is to empirically examine the health effects of such PA on key outcomes in large longitudinal cohorts using wearable monitors and to develop environmental and clinical programmes promoting high-quality

A

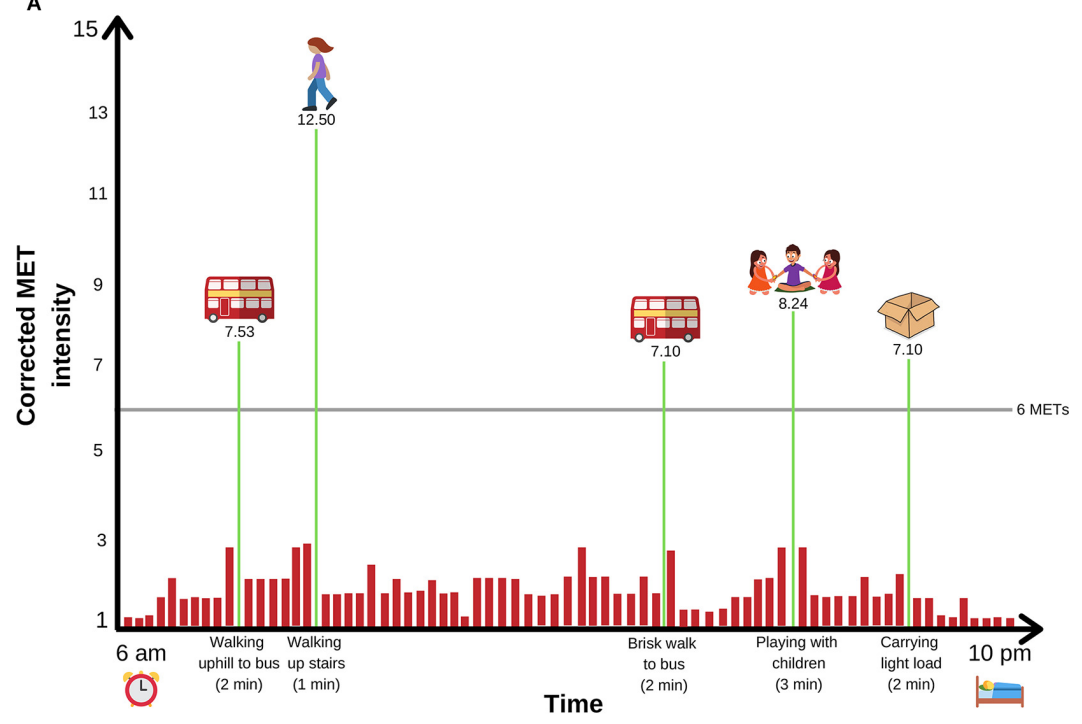

B

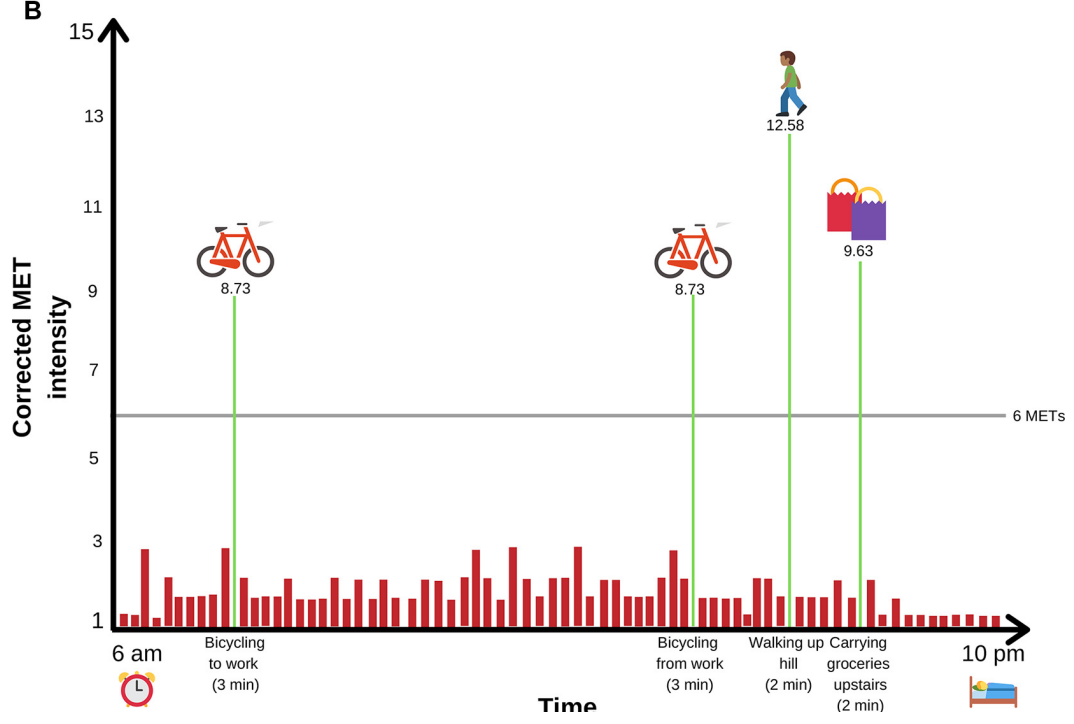

Figure 1 Hypothetical examples of a sporadic incidental vigorous PA pattern for two otherwise physically inactive individuals. (A) Corrected ${ }^{*}$ MET intensities are based on a 60 -year-old woman, $72 \mathrm{~kg}$ and $162 \mathrm{~cm}$ tall (BMI 27). Activities shown include walking, 2.9-3.5 mph, uphill, $1 \%-5 \%$ grade (Compendium code 17210); stair climbing, fast pace (17134); walking, $4.0 \mathrm{mph}$, level, firm surface, very brisk pace (17220); walking/running, playing with child(ren), vigorous effort, only active periods (05180); moving, lifting light loads (05121). (B) Corrected* MET intensities are based on a 55-year-old man, $85.9 \mathrm{~kg}$ and $175.6 \mathrm{~cm}$ tall (BMI 27). Shown activities include bicycling to/from work, self-selected pace (01011); walking, $5.0 \mathrm{mph}, 3 \%$ grade (17235); carrying groceries upstairs (05056). * MET intensities corrected based on Harris-Benedict RMR. ${ }^{6}$ Corrected $\mathrm{MET}=$ Compendium of $\mathrm{PA}^{7}$ assigned MET value $\mathrm{x}$ (3.5/Harris-Benedict predicted RMR). ${ }^{6}$ MET, metabolic equivalent; PA, physical activity; RMR, resting metabolic rate.

incidental PA during daily living. On top of 'move as often as possible and sit less', ${ }^{1}$ public health and clinical practice could emphasise simple messages analogous to 'huff and puff regularly'.

Contributors ES: drafted the manuscript. All authors contributed to re-drafting and revisions of the manuscript and approved the final version.

Funding The authors have not declared a specific grant for this research from any funding agency in the public, commercial or not-for-profit sectors.

Competing interests None declared.
Provenance and peer review Not commissioned; internally peer reviewed.

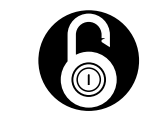

\section{OPEN ACCESS}

Open access This is an open access article distributed in accordance with the Creative Commons Attribution Non Commercial (CC BY-NC 4.0) license, which permits others to distribute, remix, adapt, build upon this work non-commercially, and license their derivative works on 
different terms, provided the original work is properly cited, appropriate credit is given, any changes made indicated, and the use is non-commercial. See: http:// creativecommons.org/licenses/by-nc/4.0/.

(C) Author(s) (or their employer(s)) 2019. Re-use permitted under CC BY-NC. No commercial re-use. See rights and permissions. Published by BMJ.

- Additional material is published online only. To view please visit the journal online (http://dx.doi.org/ 10.1136/bjsports-2018-100397).

\section{D) Check for updates}

To cite Stamatakis E, Johnson NA, Powell L, et al. Br J Sports Med 2019;53:1137-1139.

Accepted 31 January 2019

Published Online First 20 February 2019

Br J Sports Med 2019;53:1131-1140. doi:10.1136/bjsports-2018-100397

\section{REFERENCES}

1 Piercy KL, Troiano RP, Ballard RM, et al. The physical activity guidelines for americans. JAMA 2018;320:2020.

2 Jenkins EM, Nairn LN, Skelly LE, et al. Do stair climbing exercise "snacks" improve cardiorespiratory fitness? Applied Physiology, Nutrition, and Metabolism. 2019. [Epub ahead of print].

3 Oja P, Kelly P, Pedisic Z, et al. Associations of specific types of sports and exercise with all-cause and cardiovascular-disease mortality: a cohort study of 80306 British adults. Br J Sports Med 2017;51:812-7.

4 Tremblay MS, Esliger DW, Tremblay A, et al. Incidental movement, lifestyle-embedded activity and sleep: new frontiers in physical activity assessment. Can J Public Health 2007;98 Suppl 2:S208-S17.

5 Byrne NM, Hills AP, Hunter GR, et al. Metabolic equivalent: one size does not fit all. J Appl Physiol 2005;99:1112-9.
6 Kozey S, Lyden K, Staudenmayer J, et al. Errors in MET estimates of physical activities using $3.5 \mathrm{ml} \times \mathrm{kg}(-1)$ $x \min (-1)$ as the baseline oxygen consumption. J Phys Act Health 2010;7:508-16.

7 Ainsworth BE, Haskell WL, Herrmann SD, et al. 2011 Compendium of physical activities: A second update of codes and MET values. Med Sci Sports Exerc 2011:43:1575-81.

8 Batacan RB, Duncan MJ, Dalbo VJ, et al. Effects of high-intensity interval training on cardiometabolic health: a systematic review and meta-analysis of intervention studies. Br J Sports Med 2017:51:494-503.

9 Gebel K, Ding D, Chey T, et al. Effect of moderate to vigorous physical activity on all-cause mortality in middle-aged and older australians. JAMA Intern Med 2015:175:970-7.

10 Schnohr P, Marott JL, Jensen JS, et al. Intensity versus duration of cycling, impact on all-cause and coronary heart disease mortality: the Copenhagen City Heart Study. Eur J Prev Cardiol 2012;19:73-80. 